\title{
Case series of Fanconi anemia in Hevi pediatric hospital-Duhok
}

\section{Abstract}

Background and objective: Fanconi anemia is a rare inherited autosomal recessive disease characterized by chromosomal instability, progressive bone marrow failure, congenital malformations, and a high propensity of malignancies. Fanconi anemia is a genetically and phenotypically heterogeneous disorder defined by cellular hypersensitivity to DNA cross-linking agents. This study aimed to review retrospectively medical history, genetics, clinical course, blood test results, complications and social issues of Fanconi anemia patients.

Methods: All the patients with Fanconi anemia included in the study had been diagnosed between August 2008 and August 2016 in the Hevi pediatric teaching hospital, Duhok, Kurdistan-Iraq. The cases identified initially, which fulfilled clinical, peripheral blood and bone marrow examination (aspirate and biopsy) and confirmed by the cytogenic study as criteria of inherited hypoplastic anemia. Other causes of aplastic marrow were excluded.

Results: The study includes 30 Fanconi anemia cases, the median age at diagnosis was 7.5 years (range 1.5-15); At diagnosis the most blood parameters were reduced hemoglobin $(63 \%)$, reduced platelets $(57 \%)$ followed reduced leukocytes $(53 \%)$ and $9(30 \%)$ cases, all three peripheral blood count elements were reduced. Moderate aplastic anemiawas predominant, and common symptom (20 cases, 66.7\%) was hemorrhagic diathesis at presentation. Common physical abnormalities were skin pigmentation $(70 \%)$, short stature $(66.7 \%)$, thumb deformity $(56.7 \%)$, and $(53.3 \%)$ of the patients had small faces and eyes. Up to $33.3 \%$ of all Fanconi anemia patients exhibit none of the physical findings.

Conclusion: Fanconi anemia is a rare genetic disease in Duhok area; most patients were of moderate aplastic anemia, the bleeding tendency was the chief complaint of presentation. The diagnosis of Fanconi anemia in the early stage is important to select special management.

Keywords: Fanconi anemia; Hevi pediatric hospital; Duhok city.

\section{Introduction}

Fanconi anemia (FA) is a rare hereditary autosomal recessive disease characterized by chromosomal instability, cellular hypersensitivity to DNA cross-linking agents, genetically and phenotypically heterogeneous disorder defined by progressive bone marrow failure, congenital malformations, and a high tendency of tumors, including hematological malignancies and certain solid tumors. ${ }^{1,2}$ The first description of FA cases associated with developmental defects was by the Swiss pediatrician Guido Fanconi in $1927 .^{3}$ Biallelic mutations in 1 of 17 genes (called FA complementation groups $A$ through $Q$ ) involved in DNA repair processes are causes of $F A .{ }^{2,4}$ The fundamental cause is genomic instability resulting from the lack in the reproduction dependent DNA cross-link repair pathway usually referred to as the FA/BRCA pathway. ${ }^{5}$ Usually, FA diagnosis depends on clinical suspicion and chromosomal hypersensitivity to DNA cross-linking agents. ${ }^{6}$ The characteristic

* Department of Pathology, College of Medicine, University of Duhok, Duhok, Iraq. 
high degree of genomic instability of FA patients is the susceptible cause of increased cancers. ${ }^{7}$ The only known curative treatment is a hematopoietic stem cell transplant. ${ }^{8}$ The study intends to review retrospectively medical history, clinical course, blood test results, genetics, management and social issues of patients diagnosed as FA in Hevi pediatric hospital over the last eight years. This study aimed to assess the clinical behavior, diagnosis, management and follow up of individuals affected by the genetic disease. It is hoped that such a review will enable physicians in this region to betterunderstand, manage and predict the outcome of this complex disease.

\section{Methods}

Included FA patients in the study had been diagnosed between August 2008 and August 2016 in the Hevi pediatric teaching hospital, Duhok, Kurdistan-Iraq, the laboratory handles all pathological specimens of children from Duhok area, thus ensuring the most accurate way of tracing all cases with diagnostic confirmation. The cases identified initially, which fulfilled clinical, peripheral blood and bone marrow examination (aspirate and biopsy) criteria of inherited hypoplastic anemia. At the time of FA diagnosis, informationwas registered by the author

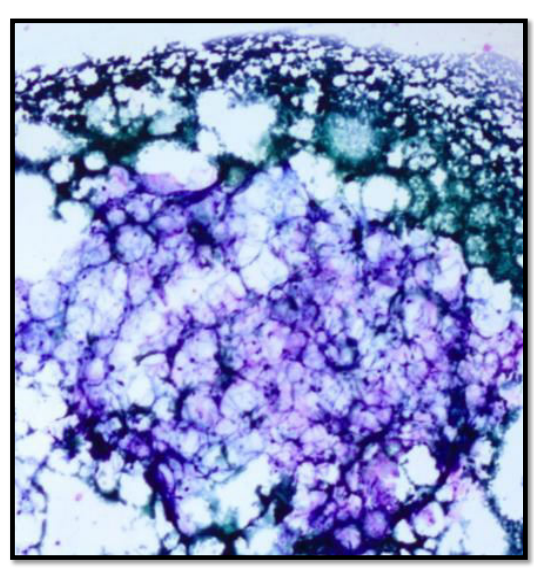

Hypo cellular bone marrow aspiration who includes hematological and congenital abnormalities, as well as any record of neoplastic progress. All the patients enrolled underwent investigations:-

- Complete blood count, including reticulocyte count, blood morphology.

- V Fetal hemoglobin assessment.

Examination of bone marrow elements, including aspirate and trephine biopsy (Figure 1).

- Cytogenetic study of peripheral blood, Mitomycin C (MMC) test was done to confirm FA (Figure 2).

- Abdominal ultrasound scan: for detection any internal abnormalities, especially for kidneys.

At least the below two of the three peripheral blood count criteria, together with a compatible bone marrow study (Hypocellularity $<30 \%$ ) were the eligible patients of the study: ${ }^{9}$

- White blood cell count $<3.5 \times 10^{9} / \mathrm{L}$,

- Platelet count $<50 \times 10^{9} / \mathrm{L}$,

- Hemoglobin count $<100 \mathrm{~g} / \mathrm{L}$ or PCV $<30 \%$. If the latter measure was one of the two satisfied, a reticulocyte count $<30 \times 10^{9} / \mathrm{L}$ was also essential.

The accepted criteria for defining the severity of aplastic anemia was described by Camitta et al. ${ }^{9}$ Very severe aplastic anemia (VSAA) is extreme absolute neutrophils count $(\mathrm{ANC})\left(<0.2 \times 10^{9} / \mathrm{L}\right) .^{10}$

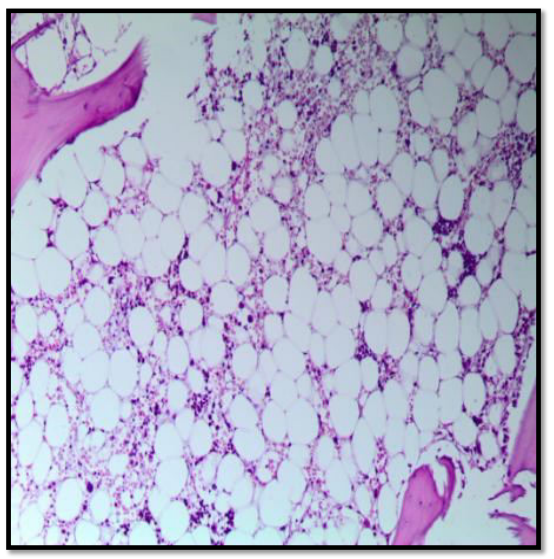

Hypo cellular bone marrow biopsy

Figure 1: Hypocelllar bone marrow tissue in Fanconi anemia. 
There are three broad category classifications of bone marrow failure, depending upon the degree of cytopenia as observed in Table 1. These descriptions are important for management options. These cytopenias must be persistent, not transient or due to another secondary cause like infection or nutritional deficiencies. To rule out alternative diagnoses, the final gutting of cases in addition to the study required a feature hypocellular bone marrow biopsy devoid of gross marrow fibrosis and lack of infiltration of cancer cells. Any patients who managed, by chemotherapy, immunotherapy or radiotherapy were excluded. Other inherited marrow aplasia was also conditioned for exclusion. The study was accepted by the ethics committee at the College of Medicine, University of Duhok, Kurdistan, Iraq.

\section{Results}

recorded as FA. Nine cases were excluded from the analysis including five patients who did not satisfy the inclusion criteria in relation to either bone marrow or blood evaluations and four patients were misdiagnosed as FA but were actually acquired aplastic anemia. This has left 30 confirmed FA cases in the register. There were 19 male and 11 female patients (M:F ratio 1.8:1). The median age was 7.5 years (range 1.5-15); with about two thirds (20 cases, $66.7 \%)$ being diagnosed in the age group 5-10 years.

Table 1: The severity of bone marrow failure. ${ }^{11}$

\begin{tabular}{lccc}
\hline & Mild & Moderate & Severe \\
\hline Absolute neutrophil count (ANC) & $<1.5 \times 10^{9} / \mathrm{L}$ & $<1.0 \times 10^{9} / \mathrm{L}$ & $<0.5 \times 10^{9} / \mathrm{L}$ \\
Platelet count & $150-50 \times 10^{9} / \mathrm{L}$ & $<50 \times 10^{9} / \mathrm{L}$ & $<30 \times 10^{9} / \mathrm{L}$ \\
Hemoglobin level & $\geq 80 \mathrm{~g} / \mathrm{L}$ & $<80 \mathrm{~g} / \mathrm{L}$ & $<80 \mathrm{~g} / \mathrm{L}$ \\
\hline
\end{tabular}

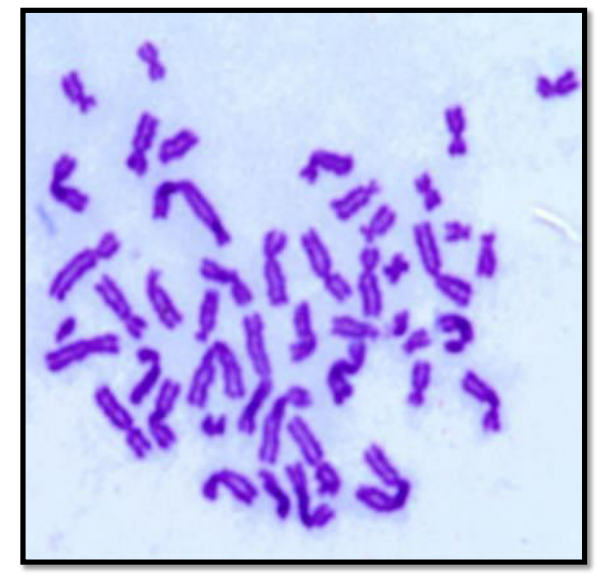

No Chromosomal breakage, Negative result

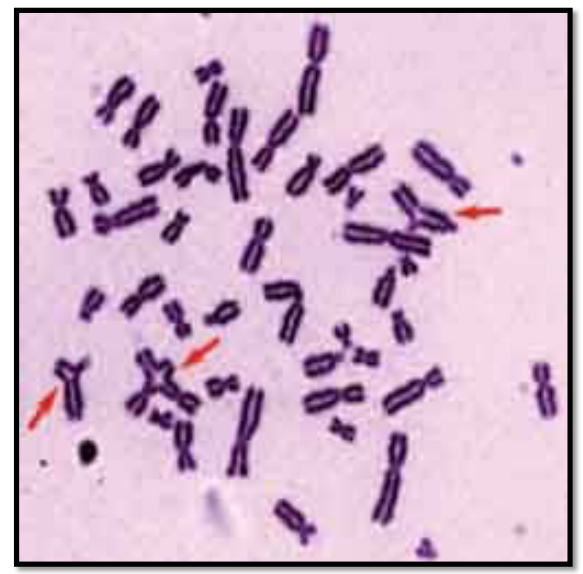

Chromosomal breakage, Positive result

Figure 2: Assessment of mitomycin C sensitivity in Fanconi anemia. 
According to the blood parameters of FA cases at diagnosis, the most frequently encountered was reduced hemoglobin followed by reduced platelets and reduced leukocytes (Table 2). Reticulocyte counts were $<30 \times 10^{9} / \mathrm{L}$ in 19 of 30 cases. In 9 cases, all three peripheral blood count elements were reduced, thus pancytopenia, while 21 cases presented hematological bicytopenia. Fetal hemoglobin $(\mathrm{HbF})$ in $90 \%$ was increased range between $2-10 \%$.The very severe aplastic anemia (AA) was diagnosed in 1 case, severe $A A$ of 2 cases, and followed by mild $A A$ in 8 cases. While the most frequent category was moderate AA (15 cases, 50\%) (Table 2), and (4 cases, 13.3 $\%)$ had normal absolute neutrophils count. The most common symptom (20 cases, $66.7 \%$ ) leading to the first contact with a pediatrician was hemorrhagic diathesis (mostly epistaxis, purpura and petechis) at presentation. Other symptoms leading to the first consultation were fatigue and pallor in (4 cases, $13.3 \%)$ and infection in (1 case, $3.3 \%$ ). The remaining 5 cases $(16.7 \%)$ had failed to thrive, short stature or were screened because they were sibs of known cases FA.

Table 2: Hematological presentation of FA cases at diagnosis, before transfusion.

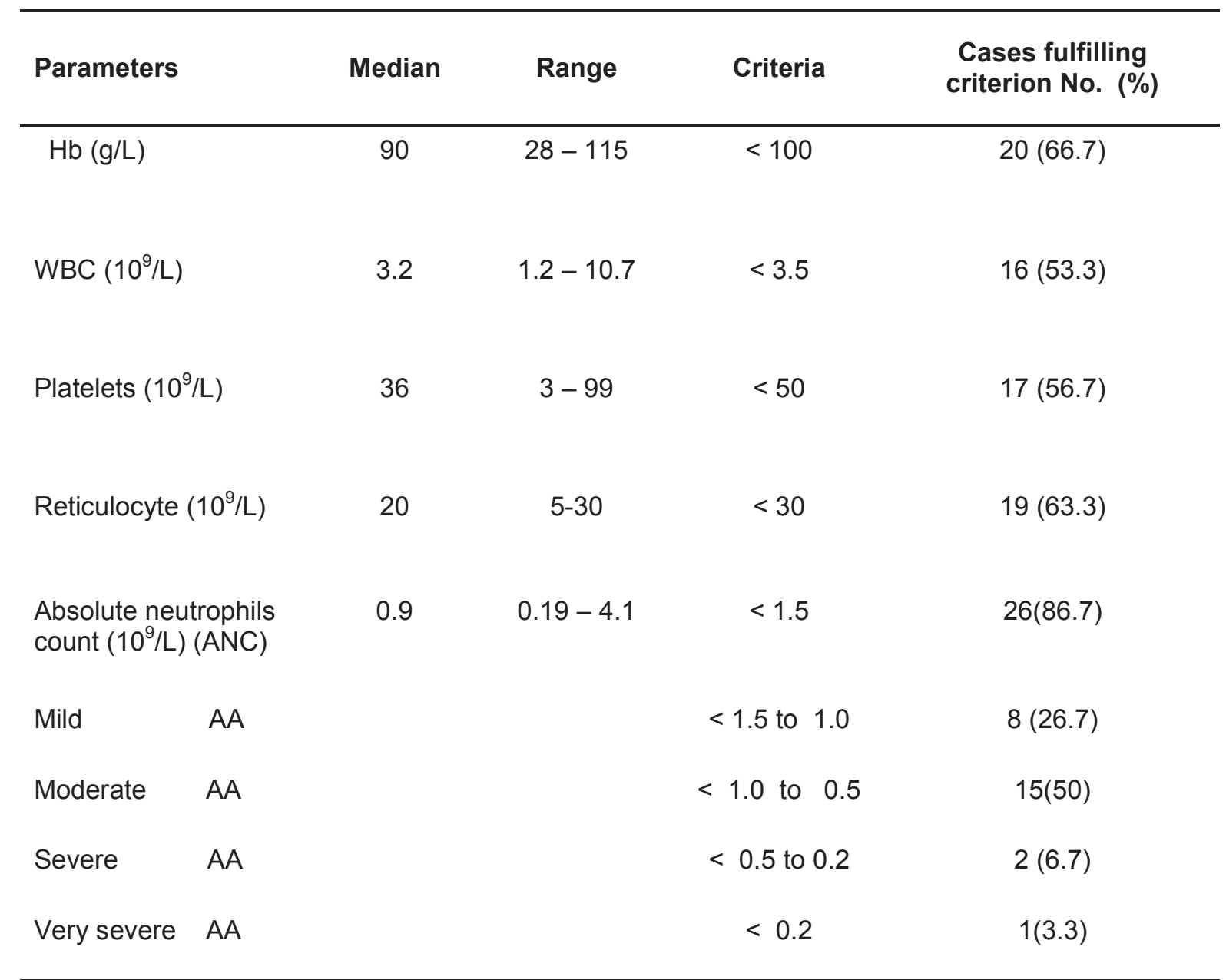


Skin pigmentation $(70 \%)$ includes café au lit, hyperpigmentation, hypopigmentation (Figure 3 ), and short stature $(66.7 \%)$ were the most common physical abnormalities
(Table 3), followed thumb deformities (Figure 4) as most skeletal abnormalities $(56.6 \%)$.

Table 3: Frequency of physical abnormalities in Fanconi anemia.

\begin{tabular}{lcc}
\hline Abnormalities & No of cases & $\%$ \\
\hline $\begin{array}{l}\text { Skin pigmentation (hyper- and hypopigmentation, } \\
\text { café au lait) }\end{array}$ & 21 & 70 \\
Short stature & 20 & 66.7 \\
$\begin{array}{l}\text { Skeletal deformity (Thumb, radial ray, hip, vertebral } \\
\text { scoliosis, others) }\end{array}$ & 17 & 56.7 \\
Small faces (microcephaly), small eyes & 16 & 53.3 \\
(microphthalmia) & & \\
Renal and urinary tract deformity & 8 & 26.7 \\
Cardiac abnormalities & 2 & 6.7 \\
Hearing loss & 1 & 3.3 \\
No abnormalities & 10 & 33.3 \\
\hline
\end{tabular}
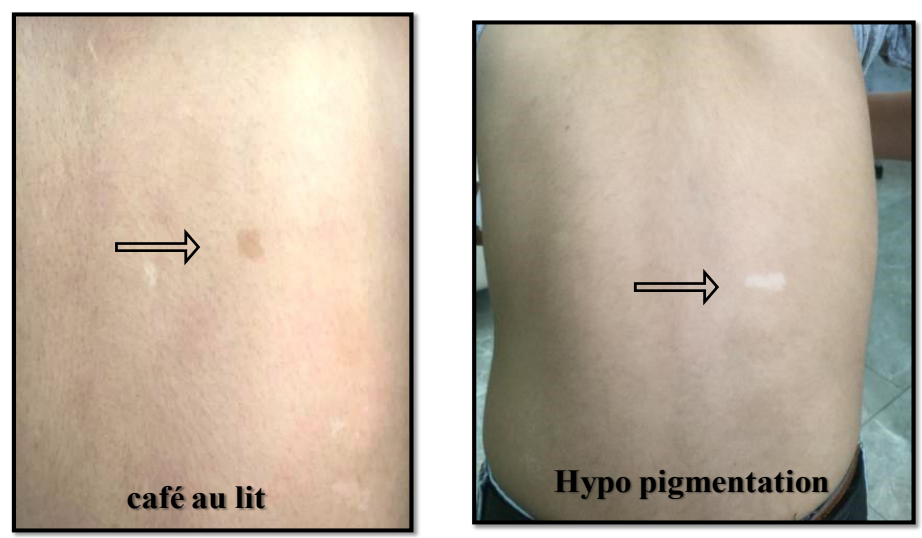

Figure 3: Skin pigmentation lesions.
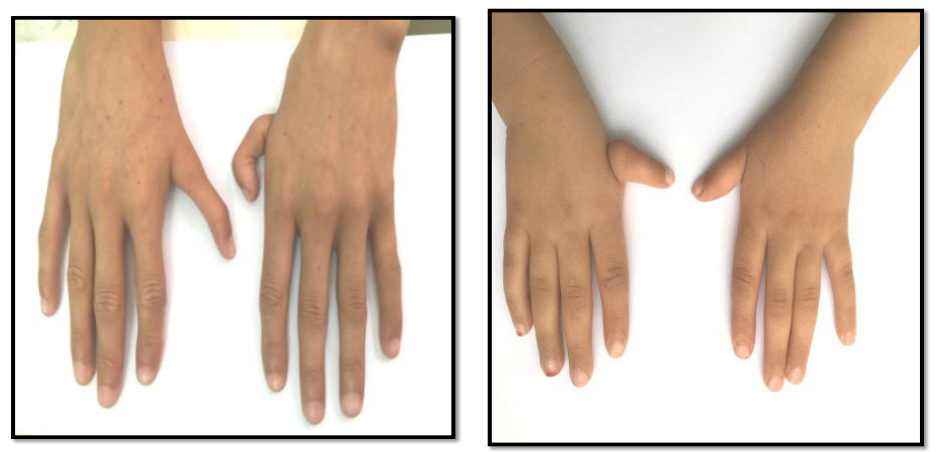

Figure 4: Skeletal (thumb) deformities. 
About half of the patients $(53.3 \%)$ had small faces (microcephaly) and small eyes (microphthalmia) as in (Figure 5). Renal abnormalities, including unilateral renal aplasia, renal hypoplasia, or horseshoe kidney were present in $26.7 \%$ of the patients. Two patients complained of cardiac abnormality, and one of them was operated for congenital heart disease. Other rare deformities include absent or hypoplastic radii, and conductive deafness had been present only in one case. Up to $33.3 \%$ of all FA patients exhibit none of the physical findings (Table 3). In August 2016 the study closing date, three out of 30 patients died $(10 \%)$, and two patients underwent hemopoietic stem cell transplantation in India. Of the three cases that died,two of them developed acute myeloidleukemia and the cause of death of the $3^{\text {rd }}$ one was unknown.

\section{Discussion}

Fanconi anemia is an inherited recessive disorder that leads to bone marrow failure (aplastic anemia. The description of the natural history of FA patients was potentially limited due to a small number of cases and short follow up. The series figure in this study has been fairly reliable since almost all cases in the Duhok area (population about $1,420,000)^{12}$ were included prospectively through our duty in the hematology laboratory during the period of the study, thus, unlikely that we missed a considerable proportion of cases.
Although diagnostic methods have enhanced recently, the incidence rates remained unwavering over the study period. The annual registration in the study was $2.7 \mathrm{per} / \mathrm{million} /$ year; the figure is similar to the prevalence were obtained in Europe and Turkey. ${ }^{13}$ The majority FA patients' progress bone marrow failure culminating in bicytopenia or pancytopenia and aplastic marrow. Most of the patients included in the study initially presented with bleeding tendency either mucocutaneous bleeding like ecchymosis and epistaxis which was due to thrombocytopenia from bone marrow failure. The latter was followed by anemia and physical abnormalities. The median age of presentation and diagnosis was 7.5 years; these results are consistent with worldwide figures, as the study of an International Fanconi Anemia Registry (IFAR) reported FA first presentation at the age between 3-10 years. ${ }^{14,15}$ At birth the FA patients had normal blood counts, which is expected in this disorder, therefore, normal blood counts at birth do not exclude FA as a possible diagnosis. ${ }^{16}$ In our study, actually platelet $\left(<50 \times 10^{9} / \mathrm{L}\right)$ was in around $60 \%$. Initially, the reduced platelet count $\left(<100 \times 10^{9} / \mathrm{L}\right)$ will nearly be the first abnormal hematological defect. This occurs in cases with both sudden and gradual onset, ${ }^{17}$ the second most often affected cell lines are the erythrocyte line, whereas the ANC was normal in $13 \%$. Fifteen cases $(50 \%)$ complained of mild
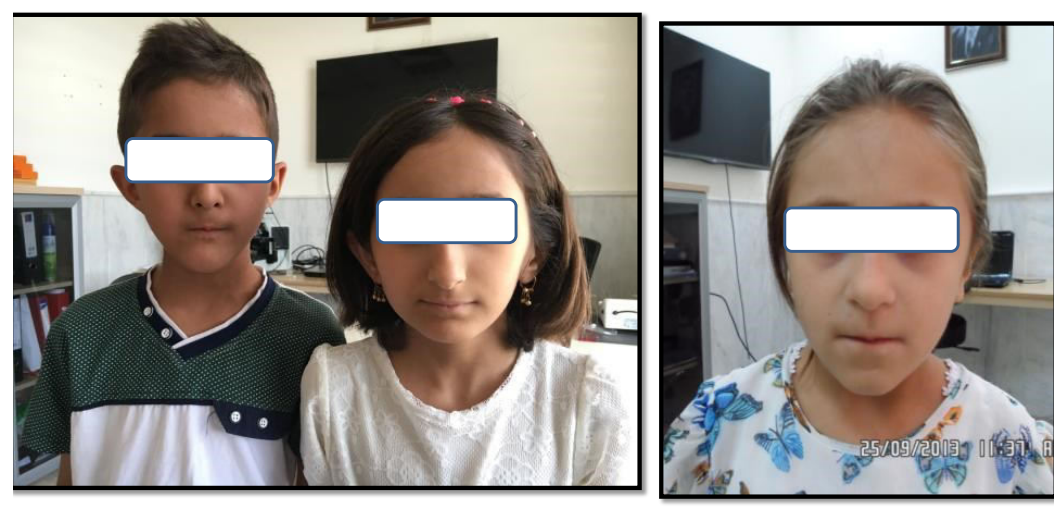

Figure 5: Small faces of three children of Fanconi anemia. 
bone marrow failure, 12 cases (40\%) marrow failure were moderate in only 3 cases $(10 \%)$ were presented with severe marrow failure. According to the severity of marrow failure, the diagnosis of FA was predominantly in an early stage this due to intense follow up of affected cases with the availability of hematological tests, including bone marrow examination in Hevi hospital and good coordination between laboratory and pediatric clinicians. The hematological testing is necessary because patients are at high risk of developing hematological malignancy and solid organ tumor, of the total registered patients two cases developed hematologic neoplasm (AML) after 3-4 years of diagnosis FA at the age of 12 and 15 years and managed by chemotherapy, during induction remission the patients died. Therefore, patients should be referred for $\mathrm{CBC}$ at a minimum biannually, and at least with an annual bone marrow examination. ${ }^{18}$ None of our patients developed solid tumors during the period studied, despite the worldwide reports of such occurrence, which is likely due to a shorter follow up with our patients. Patients with FA are liable to be diagnosed with a solid tumor between the ages of 2040 , while those in the general population is predisposed to be diagnosed between the ages of $50-60 .^{19}$ It was interesting to note that about $70 \%$ of the patients presented with congenital abnormalities that suggestive of $F A$, these patients need to be hematological evaluated, while those patients without specific clinical abnormality that suggest FA should be confirmed by cytogenic study through detection of chromosome aberrations in cells following culture with DNA cross linking agents such as diepoxybutane and/or mitomycin C (MMC). Multiorgan involvement of the patients in the study is comparable to ordinary physical abnormalities associated with FA. Skin pigmentation, short stature, and skeletal deformity were most predominant physical findings of the study patients $68 \%, 65 \%$ and $55 \%$, respectively, comparable to other studies these somatic abnormalities were common in FA patients as $66 \%, 50 \%$, and $71 \%$, respectively. ${ }^{18,20} \mathrm{Up}$ to $26 \%$ of patients have renal disorders, with another $6 \%$ having cardiac disorders finding in the study which comparable to the FA patients in other studies as $20 \%$ and $6 \%$ respectively. ${ }^{20}$ In addition, one case in the study complained of hearing loss $(6 \%)$, this abnormality was reported in $11 \%$ of patients with $\mathrm{FA}^{21}$ Approximately $6 \%$ of patients have developmental delay, or intellectual disability occurs in the study and is $10 \%$ of the FA population. ${ }^{20}$ In those conditions without clinically detectable congenital anomalies diepoxybutane (DEB) or mitomycin C (MMC) -confirmed diagnosis used for FA and allows the pediatricians to create a differentiation between Idiopathic aplastic anemia and inherited FA. ${ }^{22,}{ }^{23}$ Eight cases had a positive family history of siblings with $\mathrm{FA}$, this due to autosomal inheritance of FA and a chance $25 \%$ of other sibling to be affected and within families the degree of phenotypic variability was significant, as described by Koc $A$ et al. ${ }^{24}$ Of $33.3 \%$ FA cases have no obvious congenital abnormalities, and diagnosed when another sib in family is affected or when hematological problems progressed this comparable to an International Fanconi Anemia Registry study. ${ }^{25}$ The inherited FA disorder should be suspected in families with a history of cytopenias even without physical abnormalities. ${ }^{26}$ The possibility of a congenital form of aplastic anemia is suggested in children and young adults with short stature, café au lait spots and skeletal anomalies. ${ }^{27}$

\section{Conclusion}

The present study shows that FA is a rare genetic disease in Duhok area; the clinical and hematological presentation is comparable to the cases of FA in other studies. During presentation most patients were of moderate aplastic anemia, the bleeding tendency was the chief complaint of presentation, and predominant physical 
findings were skin pigmentation, short stature, and skeletal thumb deformity. The diagnosis of FA in an early stage is important to select special management, and this can be done by using highly specific test $\mathrm{DEB} / \mathrm{MMC}$ induced chromosome breakage.

\section{Competing interests}

The author declares that he has no competing interests.

\section{References}

1. Alter BP. Inherited bone marrow failure syndromes. In: Nathan DG, Orkin SH, Ginsburg $D$, Look AT, eds. Nathan and Oski's Hematology of Infancy and Childhood. $6^{\text {th }}$ ed. Philadelphia, PA: Saunders; 2003. P. 280-365.

2. MacMillan ML, DeFor TE, Young JA, Dusenbery $\mathrm{KE}$, Blazar BR, Slungaard A, et al. Alternative donor hematopoietic cell transplantation for Fanconi anemia. Blood 2015; 125(24):3798-804.

3. Lobitz S, Velleuer E. Guido Fanconi (1892-1979): a jack of all trades. Nat Rev Cancer 2006; 6(11): 893-8.

4. Wang AT, Smogorzewska A. SnapShot: Fanconi anemia and associated proteins. Cell 2015; 160(1-2): 354 e1.

5. Joenje $\mathrm{H}$, Patel KJ. The emerging genetic and molecular basis of Fanconi anemia. Nat Rev Genet 2001; 2(6):446-57.

6. Tischkowitz MD, Hodgson SV. Fanconi anemia. J Med Genet 2003; 40:1-10.

7. Alter BP. Fanconi's anemia and malignancies. Am J Hematol 1996; 53:99-110.

8. Vogelstein B, Kinzler KW. The Genetic Basis of Human Cancer. In: Vogelstein B, Kinzler KW, Auerbach AD, Buchwald M, Joenje H; Fanconi anemia. $2^{\text {nd }}$ ed. New York: McGraw-Hill; 2002. P. 317-32.

9. Camitta BM, Thomas ED, Nathan DG, Santos G, Gordon Smith EC, Gale RP, et al. Severe aplastic anemia: a prospective study of the effect of early marrow transplantation on acute mortality. Blood 1976; 48:63-9.

10. Bacigalupo A, Hows JM, Gordon Smith EC, Gluckman E, Van Lint MT, Congiu M, et al. Bone marrow transplantation (BMT) versus immunosuppression for the treatment of severe aplastic anemia (SAA): a report of the EBMT SAA Working Party. Br J Haematol 1988; 70:177-82.

11. Akiko S. Treatment of hematologic abnormalities in Fanconi Anemia. In: Eiler ME, D Frohnmayer, JD, L Frohnmayer, MSW, Kim Larsen, and Joyce Owen. Fanconi Anemia: Guidelines for Diagnosis and Management. $4^{\text {th }}$ ed.Oregon, Fanconi Anemia Research Fund, Inc.; 2014. P. 49-74.

12. Kurdistan Region Statistics Office, Kurdistan Regional Government. The map of the estimated population of Duhok governorate in districts level 2015. 2015. Retrieved 13 August 2016. http://krg.org/articles/detail.asp? Ingnr=12\&smap $=03010300 \& \mathrm{rnr}=$ 140\&anr=23911.

13. Alter BP. Clinical features of Fanconi's anemia. In: Young NS, Alter BP, eds. Aplastic anemia: acquired and inherited. Philadelphia: Saunders;1994. P. 275-308.

14. Auerbach AD, Allen RG. Leukemia and preleukemia in Fanconi anemia patients. A review of the literature and report of the International Fanconi Anemia Registry. Cancer Genet Cytogenet 1991; 51:1-12.

15. Butturini A, Gale RP, Verlander $P C$, Adler-Brecher B, Gillio AP, Auerbach AD. Hematologic abnormalities in Fanconi anemia: an International Fanconi Anemia Registry study. Blood 1994; 84:1650-5.

16. Garaycoechea JI, Patel KG. Why does bone marrow fail in Fanconi anemia? Blood 2014; 123(1):26-34.

17. Khatib Z, Wilimas J, Wang W. Outcome of moderate aplastic anemia in children. Am J Pediatr Hematol Oncol 1994; 16:80-5.

18. Eiler ME, Frohnmayer D, Frohnmayer L, Larsen K, Owen J. Fanconi Anemia: Guidelines for Diagnosis and Management. Fanconi Anemia Research Fund; Eugene, OR; 2008. 3rd Edition.

19. Morris LG, Sikora AG, Patel SG, Hayes RB, Ganly I. Second primary cancers after an index head and neck cancer: subset-specific trends in the era of human papilloma virus associated oropharyngeal cancer. J Clin Oncol 2011; 29(6):739-46.

20. Shimamura A, Atler BP. Pathophysiology and management of inherited bone marrow failure syndromes. Blood Rev 2010; 24:101-22.

21. Auerbach AD. Fanconi anemia and its diagnosis. Mutat Res 2009; 668:4-10.

22. Auerbach AD, Rogatko A,Schroeder-Kurth TM. International Fanconi Anemia Registry: relation of clinical symptoms to diepoxybutane sensitivity. Blood 1989; 73:391-6.

23. Verlandder PC, Davis JG, Auerbach AD. Diagnosis of Fanconi anemia in patients without congenital malformations: an International Fanconi Anemia Registry study. Am J Med Genet 1997; 68:58-61.

24. Koc A, Pronk JC, Alikasifoglu M, Joenje H, Altay C. Variable pathogenicity of exon 43del (FAA) in four Fanconi anemia patients within a consanguineous family. $\mathrm{Br} \mathrm{J}$ Haematol 1999; 104:127-30.

25. Giampietro PF, Verlander PC, Davis JG, Auerbach AD. Diagnosis of Fanconi anemia in patients without congenital malformations: an International Fanconi Anemia Registry study. Am J Med Genet 1997; 68:58-61.

26. Gupta V, Kumar A, Saini I, Ajid KS.Cytogenetic profile of aplastic anemia in Indian children. 
Case series of Fanconi anemia in Hevi pediatric .......

Zanco J. Med. Sci., Vol. 22, No. (2), August, 2018 https://doi.org/10.15218/zjms.2018.028

Indian J Med Res 2013; 137(3):502-6.

27. Al Suliman AM, Al Qadaiub K. A 15-year-old girl with pancytopenia and congenital defects. Ann Saudi Med 2009; 29(4):319. 